\title{
José de la Riva Agüero y Osma. Un exiliado latinoamericano a comienzos del siglo XX
}

\section{José de la Riva Agüero y Osma. A Latin American exile at the beginning of the twentieth century}

\author{
María Cristina Vera de Flachs* \\ Unc-Conicet-Argentina \\ ORCID ID: 0000-0002-5336-3222 \\ Antonio Sillau Pérez \\ Universidad de Piura-Perú \\ ORCID ID: 0000-0002-5820-5653
}

Recibido: $\quad 04 / 02 / 2021$

Aceptado: $\quad$ 24/10/2021

DOI: https://doi.org/10.20318/cian.2021.6441

Resumen: Este texto reconstruye la trayectoria del Dr. José de la Riva Agüero y Osma, uno de los referentes de la intelectualidad peruana de la primera mitad del siglo $\mathrm{xx}$, que atraviesa un proceso de exilio en los años veinte. Su biografía, ha sido elaborada en base a bibliografía especializada y a su propia obra, la que nos ha permitido conocer al personaje dentro de su generación y relacionarlo con otros estudiantes universitarios de importancia para Perú y América Latina.

Palabras clave: José de la Riva Agüero y Osma; Perú; Siglo XX; exilio.
Abstract: This text reconstructs the trajectory of Dr. José de la Riva Agüero and Osma, one of the benchmarks of Peruvian intellectuality of the first half of the twentieth century, which is going through a process of exile in the twenties. His biography has been elaborated on the basis of specialized literature and his own work, which has allowed us to meet the character within his generation and relate it to other university students of importance to Peru and Latin america.

Keywords: José de la Riva Agüero y Osma; Perú; twentiethcentury; exile.

*vera@onenet.com.ar 
Breve estado de la cuestión

En la República Argentina se vienen realizando desde hace tiempo numerosos escritos sobre los exilios de intelectuales durante los siglos XIX y XX. El tema es complejo y exige enormes desafíos, pues depende del momento que se aborde el mismo tiene distintas connotaciones. Lo cierto es que el exilio es un fenómeno que trasciende las fronteras y donde el exiliado se mueve en distintos escenarios geográficos viviendo siempre como si todo fuera temporario y pensando en el regreso.

En sus inicios el objeto de estudio de los historiadores argentinos fue analizar lo ocurrido durante las primeras oleadas migratorias con los intelectuales que procedían de distintos países europeos y que vinieron al país a iniciar los estudios científicos, tal el caso de los sabios alemanes que se incorporaron a la Universidad de Córdoba a partir de la década del setenta del siglo XIX y que fueron parte de la fundación de las Facultades de Medicina, de Ciencias Físico Matemáticas,del Observatorio Meteorológico Nacional y de la Academia Nacional de Ciencias. La obra de Humboldt y luego la de Charles Darwin, Alcides D’Orbigny y Félix de Azara amplió el campo de investigación en América.

Durante la presidencia de Domingo F. Sarmiento la designación de Hermann Burmeister, que vivía en Buenos Aires, como comisario extraordinario para dirigir e inspeccionar las creaciones de las facultades antes mencionadas incidió para contratar a un grupo de jóvenes científicos alemanes que sintieron el rigor de las políticas del canciller Bismarck que combatía el ala izquierdista de la burguesía liberal y el catolicismo político, a la vez que excluía del poder al movimiento obrero. Algunas de esas medidas incidieron para que los docentes e investigadores más comprometidos políticamente en su país decidieran venir a la Argentina. El grupo estuvo conformado por Paul G. Lorentz, Max Siewert, Wilhem Stelzner, C. Schultz Sellack, Christian August Vogler y Georg Hieronymus. La excepción la constituyó Hendrick Weyenbergh, un zoólogo holandés de nacimiento, pero con formación alemana. ${ }^{1}$ Del mismo modo llegó a la Argentina un español republicano, Juan Bialet Masse, después del fracaso de la revolución de $1868^{2}$.

\footnotetext{
${ }^{1}$ Maria Cristina Vera de Flachs, La Ciencia Joven. Prosopografia y producción científica de los académicos alemanes de la Universidad de Córdoba. 1870-1900, Córdoba, Junta Provincial de Historia de Córdoba, 2002.

${ }^{2}$ María Cristina Vera de Flachs, “Un español republicano en Argentina: Juan Bialet Massé. Sus textos de anatomía y manual de Medicina Legal” en Manuales y Textos de enseñanza en la universidad liberal. Universidad Carlos III, Madrid, 2004.
} 
Luego el foco se puso en los académicos que ante la amenaza de gobiernos autoritarios o dictatoriales durante la época de entreguerras, por razones culturales y lazos familiares, vieron a países como México o la $\mathrm{Ar}$ gentina como destinos donde desarrollarse económica y culturalmente. Preferentemente hubo mayor proporción de españoles, italianos y franceses. A todos ellos Argentina dio plena acogida en su vida cultural y académica. Se destacan en este periodo un grupo de españoles notables entre los que podemos mencionar a Rafael Alberti, Claudio Sánchez Albornoz, Diego Abad de Santillana, Ricardo Baeza, si bien nacido en Cuba desarrolló su labor en España hasta su exilio en Argentina, o un filósofo italiano Rodolfo Mondolfo, que dictó clases en cuatro universidades públicas.

A partir de los años noventa del silo XX un sinnúmero de investigadores argentinos se preocuparon por lo ocurrido durante las dos últimas dictaduras militares de dicha centuria (1966-1970 y 1976-1983), periodos en que el país sintió el desplazamiento de técnicos, científicos e intelectuales expulsados por la intolerancia política. El tema se fue ampliando y produciendo trabajos, desde distintas disciplinas y basados en distintos tipos de fuentes, los que fueron presentados en jornadas, congresos y encuentros donde se fue analizando el problema en distintos momentos, lo que nos sirvió de fundamentos teóricos para estudiar la problemática del exilio, y para comprender el derrotero de un intelectual peruano durante su desarraigo y luego su vuelta a su país natal ${ }^{3}$.

El tema del exilio presenta en ese periodo características específicas que lo distinguen de otros procesos anteriores y abarcó a un sinfín de personas entre militantes políticos, estudiantiles, profesionales u otros sin militancia, pero amenazados también. Fueron flujos desorganizados que, durante varios años, vieron a México y España como los destinos preferidos, aunque

\footnotetext{
${ }^{3}$ Silvina Inés Jensen, Suspendidos de la historia, exiliados de la memoria. El caso de los desterrados en Cataluña. Tesis doctoral Universidad Autónoma de Barcelona, Barcelona, 2004. En línea http://www.tdx.cat > bitstream > handle. De la misma autora "Desafíos actuales de la historia de los exilios políticos en la argentina. diálogos con la historia reciente" en Migraciones y Exilios № 16, 2016, pp. 79-106. Federico Funes y Agustín Sanz. El exilio intelectual republicano español en Argentina: la escritura como espacio imaginario de restauración y discurso en contra del olvido en Rafael Alberti y María Teresa León, Carrera Ciencias de la Comunicación Ciudad Autónoma de Buenos Aires: Universidad de Buenos Aires, 2016. Libro digital, PDF descarga y on line, 1a ed. Facundo. Altamirano, “' Intelectuales, exilio y comunicación en el Instituto Latinoamericano de Estudios Transnacionales (ILET) (19751984). Revista De La Red Intercátedras De Historia De América Latina Contemporánea, (13), 2020, pp. 250-278. Recuperado a partir de https://revistas.unc.edu.ar/index.php/RIHALC/article/view/31757
} 
también hubo en menor medida desplazamientos a Francia, Holanda, Suecia y EE.UU y algunos países sudamericanos como Venezuela y Brasil ${ }^{4}$.

En el caso del exilio de nuestro biografiado se refiere a un desplazamiento originado por una circunstancia política. Razón por la que nos extenderemos en analizar la situación sociopolítica de Perú. En esta nación, no hubo flujos comparables a los verificados en el cono sur sudamericano o México, la inmigración china, japonesa o italiana se dio en cuotas muy menores y por distintas razones. No obstante, el siglo XX ha sido testigo de los destierros de figuras del ámbito político y cultural.

La dictadura civil de Augusto B. Leguía, iniciada el 4 de julio de 1919, apuntaba, entre otras cosas a consolidar el aparato burocrático del Estado, perseguía la incorporación del país a un nuevo circuito comercial presidido por los Estados Unidos ante el desplazamiento de Inglaterra del dominio mundial y se proponía ampliar la base social en la que se asentaba el poder permitiendo el ingreso de los sectores medios. Rápidamente, la aristocracia y los apellidos ilustres, que habían tenido presencia y controlado el poder desde el civilismo se replegaron. Paralelamente, en la Universidad de San Marcos en los años veinte se concitaba una alianza social de corte clasista entre las centrales obreras y las organizaciones estudiantiles. En esos años figuras políticas, intelectuales y estudiantes salieron de Perú, algunos vieron la posibilidad de ir a la Argentina donde muchos jóvenes, entre ellos Víctor Raúl Haya de la Torre, habían establecido vínculos con Alfredo Palacios, José Ingenieros, Manuel Ugarte y Deodoro Roca, líderes de la reforma de 1918, mientras otros partieron a España, tal el caso del intelectual y político José de la Riva Agüero y Osma 5 .

El tema del exilio peruano continua en los años cincuenta, durante la dictadura de Manuel A. Odría, la nueva proscripción del Partido Aprista Peruano (que regía desde los últimos días del gobierno de Bustamante y Rivero), generó la expulsión de varios de sus líderes, incluyendo nuevamente al propio Haya de la Torre, esta vez en su "exilio" en la Embajada de Colombia de 1949 a 1954, cuando consiguió el salvoconducto para abandonar el Perú hasta 1957.

\footnotetext{
${ }^{4}$ Ver entre otros autores, Laura Rodríguez, Universidad, peronismo y dictadura, 1973-1983, Buenos Aires, Prometeo, 2015. Pablo Buchbinder, "La Universidad de Buenos Aires bajo la dictadura. Una aproximación a través del perfil, discurso y pronunciamientos públicos de dos de sus rectores" en CIAN, Revista de Historia de las Universidades, 19/2, 2016, pp. 154-173. Loris Zanatta, La larga agonía de la Nación Católica, Buenos Aires, Sudamericana, 2015. Marcos Novaro y Vicente Palermo, La dictadura militar 1976/1983, Buenos Aires, Paidós, 2001.

${ }^{5}$ Martín Bergel, Manuel Seoane y Luis Heysen, " El entre lugar de los exiliados apristas peruanos en la Argentina de los veinte". Políticas de la Memoria, 6/7, 2006-2007, pp. 124-142.
} 
La dictadura militar de Juan Velasco también cuenta con su historial de exiliados, como fue el caso del ex presidente Fernando Belaúnde, derrocado en 1968 por aquel, el también ex presidente Pedro Pablo Kuczynski (siendo funcionario del gobierno de Belaunde), líderes del partido del gobierno derrocado: Acción Popular, o también el humorista e intelectual Luis Felipe Angell ("Sofocleto"). En los años noventa el régimen de Alberto Fujimori también provocó expatriaciones, siendo el caso más emblemático el del ex presidente Alan García en París.

Pero el Perú también ha sido destino de exiliados procedentes de diversos países. Entre 1964 y 1971 y 1974 a 1976 se exilió en Lima el ex presidente de Bolivia e intelectual, Víctor Paz Estenssoro. También, el periodista y escritor chileno José Rodríguez Elizondo, ex funcionario del gobierno de Salvador Allende, luego de abandonar Chile, tras el golpe de Estado de Augusto Pinochet y de su exilio inicial en Europa, emigró a Lima en 1977 y permaneció allí durante los años ochenta. Más recientemente, el país también ha sido testigo de los exilios procedentes desde Venezuela. Como en otras partes de América Latina, los contingentes migratorios venezolanos que huyen de la crisis del régimen chavista comparten su realidad con el exilio de líderes políticos, sindicalistas, empresarios, militares, profesionales e intelectuales. Al Perú llegaron figuras como Oscar Pérez, ex diputado y actual presidente de la ONG "Unión Venezolana en Perú"; también el ex alcalde de Maracaibo y gobernador del estado Zulia, Manuel Rosales entre 2009 y 2015. También la figura del líder de la Confederación de Trabajadores de Venezuela, Carlos Ortega Carvajal, quien escapó de una prisión militar venezolana y se asiló en el Perú desde 2007. Esta larga historia de exilios desde y hacia el Perú de figuras diversas de la política y la cultura puede constituir, por cierto, una muestra de algunos rasgos claves que han perdurado en la historia política contemporánea de América Latina: su inestabilidad recurrente y la debilidad de sus instituciones.

En síntesis, si bien la problemática del exilio intelectual no es nueva en la historia latinoamericana, pensamos que hay que seguir profundizándola y estudiar casos menos conocidos como el que presentamos ${ }^{6}$.

Este trabajo se articula en tres líneas de análisis. Por un lado, haremos referencia a una breve biografía de José de la Riva Agüero y Osma con la idea

${ }^{6}$ Algunos trabajos que pueden remitirnos a la problemática histórica del exilio desde y hacia América Latina: Walther L. Bernecker (comp.). Memoria histórica, análisis del pasado y conciencia colectiva: casos latinoamericanos. México: Universidad Nacional Autónoma de México, 2003. Francisco Caudet. Hipótesis sobre el exilio republicano de 1939. Madrid: Fundación Universitaria Española, 1997. Francisco Madrid. Los desterrados de la dictadura: reportajes y testimonios Madrid: España, 1930. 
de reconstruir su trayectoria académica, para ello nos valdremos de la bibliografía sobre el personaje y de sus Obras Completas que nos permitieron conocer su vida, pensamiento y trayectoria ${ }^{7}$. Luego haremos referencia a sus años de exilio para ocuparnos finalmente de su vida al regreso al Perú. Preguntándonos ¿Por qué se fue? ¿Qué ideas trajo de la vida, del mundo y del trabajo intelectual realizado en su exilio?, ¿Cambió su manera de pensar? ¿Tuvieron sus ideas algún impacto en el Perú? ¿Qué hizo hasta el fin de su vida?

En este sentido, vale aclarar que si bien nuestra investigación se plantea como una historia de un intelectual en el exilio, dado nuestra preocupación por los problemas universitarios nos interesa incluir en este proceso el marco del clima intelectual que se vivía en su país natal durante la etapa de su formación. La influencia de algunos personajes de la época sobre él, sus compañeros de estudio y los cambios políticos que se produjeron a lo largo de su vida. Creemos que repensar el personaje, un tanto olvidado, vale la pena en tanto él, como sus compañeros de estudios, representa el inicio del pensamiento sociopolítico del Perú del Siglo XX.

\section{El protagonista de la Historia}

Censurado por los ignorantes, menospreciado por los bribones y mofado por los viles, ese ha sido mi destino ${ }^{8}$.

José de la Riva Agüero y Osma (nació y falleció en Lima 26 de febrero de188515 de octubre de 1944) proviene de una vieja y opulenta familia aristocrática, tradicionalmente ligadas al campo político e intelectual del Perú. José conocido también como VI marqués de Montealegre de Aulestia y V marqués de la Casa Dávila, era bisnieto del primer presidente del Perú, José de la Riva Agüero y Sánchez-Boquete (1823), con relaciones con Argentina. Hijo único y huérfano de padre desde muy pequeño era heredero de una cuantiosa fortuna, pero consagró su vida al cuidado de su madre y de una tía. Inició sus estudios escolares en 1893 en el Colegio Sagrados Corazones, más conocido como Recoleta de Lima en el que se graduó en 1901. No fueron años muy felices para él. Su afición a las letras, su delicada salud y no ser muy apreciado por muchos de sus compañeros hicieron que prefiriera pasar el tiempo en la biblioteca de su casa.

\footnotetext{
${ }^{7}$ José de la Riva Agüero y Osma, Obras Completas de..., Editorial: Pontifica Universidad Católica del Perú, Lima, Perú, 1962.

${ }^{8}$ José de la Riva Agüero y Osma, "Entrevista con Alfonso Tealdo" en Turismo Lima, Nro. 62, 1941, p. 12.
} 
En 1902, junto a Francisco García Calderón ${ }^{9}$ (1883-1953) y Víctor Andrés Belaúnde ${ }^{10}$ (1883- N. York, 1966), José cursó la carrera de Filosofía y Letras en la Universidad Nacional Mayor de San Marcos, una temprana creación del régimen colonial del siglo XVI. ${ }^{11}$ Para comienzos del siglo XX esa institución era la encargada de formar los cuadros aptos para participar y consolidar instituciones nacionales. Los tres jóvenes antes mencionados provenían de familias aristocráticas y ligadas al campo político e intelectual del Perú, frecuentaban los mismos círculos de la sociedad capitalina y de otras ciudades hispanizadas, transformándose en actores fundamentales de la formación intelectual surgida en Lima hacia principios del siglo, denominada alternativamente "generación futurista", "generación arielista" o "generación del novecientos". No obstante, absorbido el positivismo reinante

${ }^{9}$ Francisco García Calderón fue hijo del presidente del Perú Francisco García Calderón Landa, ilustre jurista y rector de la Universidad Nacional de San Marcos y de Carmen Rey Basadre. Su padre siendo presidente, fue deportado a Chile y en 1884 se retiró a Europa, con su familia regresando al Perú en 1886. En 1906 regresó Francisco a vivir a Europa y en los treinta y seis años que duró su estadía desarrolló la mayor parte de su trayectoria como ensayista, desempeñando simultáneamente funciones diplomáticas para el gobierno peruano.

${ }^{10}$ Víctor Mario Rafael Andrés Belaúnde Diez-Canseco, como estudiante universitario concurrió al primer Congreso de estudiantes latinoamericanos celebrado en Montevideo en 1908. Su larga existencia le permitió destacarse como pensador, jurista, diplomático, político, intelectual, escritor y educador peruano. Católico y humanista, formó parte de la "Generación del 900". Tuvo una carrera importante y al igual que nuestro personaje sufrió el destierro al producirse el golpe de estado de Augusto Leguía. En 1918 fundó el tercer "Mercurio Peruano", revista de la que fue director hasta 1932. En 1919, bajo el segundo gobierno de Pardo fue nombrado ministro plenipotenciario en Uruguay, pero renunció. Nuevamente en el Perú, desde la Universidad de San Marcos abogó por la libertad de los presos políticos y protestó por la expropiación del diario "La Prensa". Su oposición al gobierno de Leguía motivó que sufriera persecución política. Apresado, fue confinado en la Isla San Lorenzo, y luego desterrado a Francia, donde volvió a casarse. Regreso al Perú en 1930 después de la caída de Leguía y tuvo una destacada actividad diplomática y política y fue gestor de la creación del instituto Riva Agüero en 1947. Dejó como legado cientos de artículos sobre derecho, política y relaciones internacionales que dan cuenta de su vasto conocimiento en esos campos. Entre los libros que publicó figura "La Constitución inicial del Perú ante el Derecho Internacional", considerada su obra cumbre. María C. Vera de Flachs," Un precedente de la reforma del '18: el I Congreso internacional de estudiantes americanos. Montevideo 1908" en Junta Provincial de Historia de Córdoba, Movimientos Estudiantiles en América y Europa, Tomo I, capítulo I, 2006, pp. 73-114.

${ }^{11}$ CFr. Entre otros, Carlos Daniel Valcárcel, San Marcos, Universidad Decana de América, Lima, Imp. de la Universidad Nacional de San Marcos, 1968. Antonio Eguiguren, La Universidad Nacional de San Marcos. IV centenario de la fundación de la Universidad Real y Pontificia y de su vigorosa continuidad histórica, Lima, 1960. Virginio Galdo Gutiérrez, Visión histórica de la educación peruana: etapa republicana, Lima, Fondo Editorial de la Asamblea Nacional de rectores, 2012. 
en San Marcos, adhieren tempranamente al espiritualismo del Ariel de José Enrique Rodó, por entonces de amplia acogida en las Universidades latinoamericanas. Si bien acabarían siguiendo rumbos diferentes, fueron participes de una elite intelectual interesada en integrarse a lo que estaba sucediendo en otros lugares del mundo ${ }^{12}$.

\section{Manuel González maestro para la generación del 900}

José de la Riva Agüero y Osma obtuvo en 1905 el grado de bachiller en letras con una tesis titulada El carácter de la literatura en el Perú independiente ${ }^{13} \mathrm{y}$ alcanzó el grado de doctor en el año 1910 con la sustentación de su tesis La Historia del Perú, y en 1911, el de Bachiller en Jurisprudencia con el trabajo intituladoFundamento de los interdictos posesorios. Luego realizó un viaje por pueblos de Bolivia y la sierra sur del Perú, que le permitieron escribir una serie de memorias de viaje, publicadas años después de su muerte en el libro Paisajes peruanos. De retorno a Lima, en noviembre de 1912 se graduó como abogado, con la tesis denominada Ensayo de filosofía jurídica en torno al concepto de Derecho.

Durante los años de estudios de Riva Agüero y Osma y hasta 1919, el Perú transitaba por un período de estabilidad política y consolidación de un proceso de recuperación económica luego de la posguerra con Chile. El gobierno de Nicolás de Piérola (1895-1899) inauguró un periodo particular de la historia política peruana, etapa conocida como la "República Aristocrática"14 que se prolongó hasta 1919, periodo que se gozó de gran estabilidad política en virtud que se produjeron renovaciones presidenciales a través de elecciones. Sin embargo, debemos acotar que este panorama reflejaba una renovada participación política que incluía solo a los sectores educados, en tanto la ciudadanía y el voto estaban reservados para los alfabetos, dejando de lado a los sectores populares.

La llamada elite política dio pie a un sistema partidario diverso que se disputaba el control de los poderes del Estado. Por entonces Lima, seguía siendo una ciudad católica, pero no una ciudad ferviente, sin embargo, tenía

\footnotetext{
${ }^{12}$ Martin Castilla., "La generación arielista y la construcción del "otro" en el Perú del novecientos”, en Revista: Los Trabajos y Los Días; año 3, no. 2, Facultad de Trabajo Social, La Plata, p. 141-149.

${ }^{13}$ Publicado en Lima, Librería Francesa Científica Galland, E. Rosay Editor, 1905.

${ }^{14}$ Denominación acuñada por el historiador Jorge Alfredo Basadreen Historia de la República, obra iniciada en 1939 y ampliada y mofiicada hasta 1968. 16 vol., Lima 1972.
} 
grandes manifestaciones de fe. Todo era emotivo, pintoresco y grato lo que tornaba a esta en una atractiva ciudad colonial. Sin embargo, los jóvenes estudiantes peruanos, no encajaban con esas tradiciones y. como otros, encontraban en la vida intelectual los mismos conceptos y similares sentimientos que circulaban por toda América.

Solo en 1914 esa relativa calma se vio obstaculizada por el golpe de Estado del comandante Oscar Benavides, dicha interrupción no fue un golpe militar clásico, ya que Benavides gobernó apenas unos meses y convocó a elecciones para el año siguiente, que inauguró el último gobierno del Partido Civil.

Fue durante este periodo que la economía encontró un ritmo de crecimiento y modernización, La presencia de los grandes enclaves del capital transnacional minero y petrolero como la Cerro de Pasco Corporation y la Internacional Petroleum Corporation(IPC), además del dominio del capital extranjero en la banca, el comercio exterior y los servicios públicos, se combinó con el desarrollo de la agro exportación, principalmente de azúcar, que posibilito alcanzar mayores ingresos. Antiguas haciendas de ritmo propio de la época virreinal dieron paso, gracias a las libertades económicas brindadas por el gobierno al desarrollo de verdaderos complejos agroindustriales. Este desarrollo también fue posible por un mayor despliegue de ferrocarriles y puertos, ahora conectados por vías de comunicación. Es importante también mencionar la influencia que tuvo la primera guerra mundial en la economía peruana permitiendo que se incrementase el presupuesto nacional. Pero este modelo de desarrollo favorecía principalmente al capital extranjero y a la clase propietaria peruana, en realidad, a un número importante de familias unidas por vínculos no solo comerciales sino hasta parentales, propietarias de grandes extensiones de tierra. El predominio económico del capital extranjero y de la élite peruana dio pie a que los llamados sectores populares: artesanos, campesinos y una incipiente clase obrera diesen paso a las primeras protestas y huelgas por mejoras salariales o económicas. Este modelo económico primario exportador que giraba en torno a los enclaves extranjeros y las haciendas agroexportadoras, se mantendría sin mayores cambios en el Perú en las décadas subsiguientes.

El período conocido como "República Oligárquica", llegó a su final en 1919, con el golpe de estado del ex presidente Augusto Leguía (1919-1930). Se iniciaba una larga etapa conocida como el Oncenio, debido a los once años en los que Leguía ejercería un poder dictatorial y unipartidario, los debates políticos se simplificaron entre leguistas y anti leguístas, todo opositor al régimen era perseguido o deportado y las pocas libertades existentes fueron 
paulatinamente desapareciendo. Esta situación, dio pie a que los sectores populares que apoyaban a Leguía permitieron su permanencia por más de una década, además de realizarse cambios constitucionales. A pesar de la férrea oposición, a finales de su gobierno surgirían en el Perú el núcleo de los principales partidos políticos de masas: el socialista y el aprista. La fuerte dependencia del régimen de Leguía de las inversiones y créditos norteamericanos, fue el marco en el cual se desplomó la economía peruana por efecto directo del crack de la economía de los Estados Unidos de 1929. La crisis peruana se prolongaría hasta la primera mitad de la década del treinta y arrastró políticamente el régimen de Leguía, quién fue depuesto por el golpe de estado del comandante Luis Sánchez Cerro en agosto de 1930.

Con la dictadura de Sánchez Cerro, el Perú inauguraba un nuevo periodo histórico de inestabilidad política y autoritarismo. La dictadura sanchezcerrista fue resistida por el Partido Aprista, lo que generó un nuevo enfrentamiento político y social que terminaría con el asesinato del presidente en 1933. La sucesión presidencial recayó en el general Oscar R. Benavides, quien ejerció la presidencia hasta 1939, luego de haber anulado los comicios de 1936. La anulación fue justificada con el argumento de que los votos recibidos por el candidato ganador eran apristas y por lo tanto ilegales de acuerdo a la legislación de ese entonces. Durante ese tiempo y hasta el término de la segunda guerra mundial, la economía peruana logró tener un desarrollo dinámico y sostenido debido a la gran variedad de productos de exportación (agrícolas, mineros, petróleo y lanas) que permitieron a los gobiernos de Benavides (especialmente) y de Manuel Prado Ugarteche (1938-1945 y 1956-1962) a desarrollar una política social en favor de los sectores medios y populares al desplegar programas de educación, salud y leyes en favor de los obreros.

La realidad económica peruana descrita para comienzos de siglo XX y su carácter dependiente del capital extranjero incidió tempranamente para que un intelectual peruano, Manuel González Prada, iniciara el reclamo contra esa dominación, llamando a la juventud a luchar contra esa situación. Este personaje tuvo gran influencia en la etapa estudiantil de los jóvenes de la generación del 900. ¿Pero quién era este personaje y que relación tuvo con los estudiantes antes mencionados?

Manuel González Prada nació el 5 de enero de 1844, en Lima, siendo el tercer hijo de don Francisco González de Prada y Marrón de Lombera y de doña Josefa Álvarez de Ulloa, quienes en 1838 conformaron un hogar católico, conservador y de linaje palaciego. A los siete años de edad Manuel inicio su educación escolar en Lima, que se vio interrumpida por el traslado de la familia a Chile por un lapso de dos años. En ese país fue matriculado en el Co- 
legio Inglés de Valparaíso, dirigido por un inglés y un alemán, lo que marco su personalidad. De vuelta en Lima, reanudó su escolaridad en el Seminario de Santo Toribio, que abandonó a corto plazo ${ }^{15}$.

Entre 1860 y 1864 cursó estudios en el Convictorio de San Carlos, truncando su formación profesional de abogado, por razones de su temperamento personal e incompatibilidad con sus expectativas de vida. Complementó y amplió su bagaje cultural con el autoaprendizaje proveniente de sus lecturas intensas y permanentes.

Su primera conferencia la impartió, en 1886, en El Ateneo. La misma tenía un rostro programático y contemplaba preferentemente el análisis literario peruano destacando sus debilidades como el de la limitación de los mediocres. En 1888 fue más allá y, en un discurso pronunciado en el Politea$m a$, que es una verdadera alocución política para los jóvenes, reclamó por la dominación de los terratenientes y la sujeción de las masas campesinas a la ignorancia y a la servidumbre, llamando a la juventud a luchar contra esa situación. E inició la reivindicación de la rebelión estudiantil en alianza con la protesta obrera, al señalar en su discurso: "los viejos a la tumba, los jóvenes a la obra", convocando a la lucha por el cambio social ${ }^{16}$.

Poco después, en el teatro Olimpo, arremetería contra la insignificancia y servilismo de los intelectuales reclamando a la nueva generación romper contra el pacto infame de hablar a media voz. Y posteriormente publicaba Propaganda y ataque señalando que el verdadero fundamento de la Nación lo constituían las masas indígenas y que hasta que ellas no estuvieran representadas no habría cambios en los problemas del país ${ }^{17}$.

Comprometido con la realidad política y social de la época que le tocó vivir González Prada sostuvo que, en ese momento, Perú era organismo enfermo y decía: "donde se aplica el dedo brota pus". De allí su preocupación por influir en los jóvenes. Su anticlericalismo, su posición ascética de la vida y su sensibilidad para visualizar los problemas de su país hicieron que se convirtiera en un verdadero maestro para muchos de los jóvenes de la generación novecentista.

${ }^{15}$ Luis Alberto Sánchez, Mito y realidad de González Prada Lima: P.L. Villanueva Editor, 1976, p. 74.

${ }^{16}$ Manuel González Prada, Discurso del Politeama, p. 44. El discurso fue publicado primero en el periódico Sobrevilla y compilado después, en 1894, en el libro Pájinas Libres. París, Tipo. de Paul de Dupont, 1894

${ }^{17}$ Manuel Gonzalez Prada, Pajinas...op cit., pag. 147-167. Manuel GONZÁLEZ PRADA, «Propaganda i ataque», Amerika [En ligne], 17 | 2017, mis en ligne le 01 décembre 2017, consulté le 07 mars 2020. URL : http://journals.openedition.org/amerika/8236 
De esta manera, esos universitarios admiraron su postura frente a la educación, cultura y modernización del Estado, temas que estarán presentes en los escritos de todos ellos. Al punto que Juan C. Mariátegui indicaba que González Prada fue un agitador intelectual y que, a través de sus afirmaciones, influyó en el pensamiento de los jóvenes y en la cultura peruana. Entre otras cosas, porque además lo obsesionaba el problema del indio, tema que abordaran los jóvenes de la generación del 900 y en particular Riva Agüero. Este último expresó su admiración por este "maestro". En síntesis, hacemos nuestra la definición de Manuel González Prada, realizada por el italiano Giuseppe Bellini quien señaló:

... el personaje se aventaja en el aspecto revolucionario con la difusión de su apocalíptico «Los viejos a la tumba, los jóvenes a la obra», en realidad su vida no fue la de un héroe, aunque sí la de un resistente, de un reformador de conciencias y de costumbres, un intelectual partidario y propulsor de una sociedad nueva, frente al viejo conservadurismo, que aventajaba sólo a una clase de ricos, dejando en la miseria a la parte más consistente de la población peruana. En suma, un idealista, un político atraído por la literatura, en particular por la poesía, cuyo fruto con parsimonia daba a conocer ${ }^{18}$.

Con Víctor Andrés Belaunde, Riva Agüero coincidió en su juventud en sus ideales reformistas para el Perú, en su admiración a González Prada,en la ilusión de crear,como así también en su oposición contra el presidente Leguía, lo que le costó a ambos el exilio. Pero luego sus caminos se bifurcaron. La línea divisoria se produjo porque Belaunde era más cauto y ecuánime que su amigo y creía en las reformas institucionales, lo que se manifestaba en sus primeros escritos políticos donde demostraba un perfil republicano, con clara adhesión al socialcristianismo y sus diferencias con el marxismo y aprismo, razones que lo llevaron a no apoyar al gobierno del comandante Luis M. Sánchez Cerro ni al del general Óscar R. Benavides, como sí lo hizo su gran amigo y compañero de generación, José de la Riva Agüero ${ }^{19}$. No obstante ambos vivieron la ilusión de crear el Partido Nacional Democrático, síntesis de los antiguos partidos Civil y Demócrata. El fracaso de ese partido les afectó mucho e influyó en un cierto decaimiento del que se levantaron luego con energía y en los años treinta volvieron a la lucha. Por entonces, José estaba secundado por los compañeros de Universidad

${ }^{18}$ Giuseppe Bellini (Universidad de Milán) “fortuna” literaria de Manuel González Prada "en Thomas Ward / Richard CacchioneAmendola (EDITORES) Homenaje a Eugenio Chang Rodríguez, Universidad Ricardo Palma, Editorial de la Universidad, Lima, Perú 2017, p. 26.

${ }^{19}$ Estos temas los podemos analizar gracias a algunas cartas que Belaunde intercambió con Riva Agüero en el año 1932 - año fatal para la historia peruana- y que han sido publicadas en el tomo XIII de las Obras completas del historiador limeño. 
antes nombrados, junto a otros como Francisco García Calderón, Oscar Miró Quesada y Julio C. Tello, jóvenes instruidos pertenecientes a la clase alta del Perú que poseían un sentido de la historia de su país, y que descontentos de la realidad política y cultural de su tiempo confiaron en maestros como Manuel González Prada y E. Rodo ${ }^{20}$

Esta concepción de pertenecer a un circulo de elite no se diferenciaba con la que tenían los jóvenes reformistas de la Córdoba de 1918, movimiento que tuvo amplia repercusión en Latinoamérica y particularmente en Perú en la década del veinte del Siglo XX. Y a lo que adhirieron algunos de ellos. La Reforma estudiantil había tomado una posición clara contra el imperialismo, militarismo y clericalismo, que se manifestó en la acción política de los movimientos estudiantiles a través de una cerrada oposición a los regímenes dictatoriales. La reacción nacía en cada caso, generalmente, a partir de la hostilidad que los gobiernos militares mostraron frente al movimiento reformista y con las universidades en general, a las que acusaban una y otra vez de ser focos subversivos.

\section{Riva Agüero y su primera militancia}

Fiel a sus ideas Riva Agüero tempranamente enjuiciaba en un artículo publicado en 1909 al primer gobierno del presidente Augusto B. Leguía (19081912) lo que le valió la cárcel generándose el 14 de setiembre una gran protesta universitaria, comparable según algunos, a las protestas de Víctor Haya de la Torre en 1923.

La participación en la vida política de Riva Agüero se inició el 12 de setiembre de 1911, cuando en el diario El Comercio publicó otro artículo titulado "La Amnistía y el gobierno" ${ }^{21}$, y en el que exigía al gobierno de Leguía la promulgación de una ley de amnistía para los presos involucrados en la intentona golpista del 29 de mayo de 1909. Asimismo, criticaba la situación política y social, el exceso de gastos, los empréstitos del gobierno y la debilidad del Congreso.

El gobierno, por intermedio del ministro de Gobierno, Juan de Dios Salazar y Oyarzabal, ordenó la detención de Riva Agüero. Fue entonces cuando

${ }^{20}$ Para quien quiera profundizar el tema cfr. en Teodoro Hampe Martínez, Francisco A. Calderón, América latina y el Perú del novecientos, Antologia de textos, Lima, Fondo editorial UNMSM 2003.a

${ }^{21}$ J. Riva Agüero y Osma, "La Amnistía y el gobierno", El Comercio, Lima, 12 de setiembre de 1911, p. 5-6. 
la juventud universitaria salió a protestar a las calles, gritando "abajo la dictadura" y "viva la democracia", siendo reprimida severamente por la gendarmería. Este acontecimiento constituyó el primer choque de los universitarios y la fuerza pública que se registran en los anales históricos del Perú. Esta protesta, sumada a la del parlamento y la prensa, hizo que Riva Agüero fuese puesto en libertad, e incluso provocó la caída del ministro del Gobierno.

En los choques con la policía hubo muertos, pero Riva Agüero fue liberado ese mismo día. El reclamo más fuerte de los estudiantes universitarios era que no podían expresar libremente sus ideas y en ese sentido fueron apoyados por dos periódicos El Comercio y La Prensa. Además, se hizo un acto de desagravio a la figura de Riva Agüero en el jardín zoológico de Lima al que asistieron los compañeros de su generación que luego formaron parte del Partido Nacional Democrático(PDN). En el momento, se pensó que esta propuesta de los jóvenes del 900 expresadas a través de un partido político, era solo una crítica al gobierno sin asumir una actitud de oposición.

Esto llevó a Leguía a dictar una ley de amnistía que fue aprobada por unanimidad generando, a su vez, una crisis política que concluyó con la renuncia del ministro de gobierno Sr. Juan de Dios Salazar y Oyarzabal.

Luego Riva Agüero viajó a Europa con el fin de participar en el Primer Congreso de Historia y Geografía Hispano-americano, realizado en Sevilla en 1914. A partir de 1915 inició una relación por correspondencia con su primo el historiador y publicista español Álvaro Alcalá-Galiano y Asma, a quien habría conocido en 1913 y que ostentaba el título de marqués de Castel Bravo ${ }^{22}$.

La Primera Guerra Mundial lo llevó de vuelta a Perú en compañía de su madre y su tía. Pensaba que estaba presto para la lucha política, pero pronto se dio cuenta que no era así y, en 1917, retiró su candidatura para la diputación de Lima. Sin embargo, él y sus compañeros, en sus escritos, no dejaron de trasuntar el amor por su tierra, al punto que Riva Agüero formuló esta definición:

La patria por definición y esencia, no puede ser nueva, porque representa el legado de los padres, la tradición, la herencia material y moral ampliada y mejorada, pero nunca negada y demolida ${ }^{23}$

En la década del veinte las energías del hombre americano renacieron impetuosas y prepotentes. La revolución rusa, tanto en Perú como en Argen-

\footnotetext{
${ }^{22}$ Miembro de Renovación Española Álvaro fue asesinado, junto a su hermano, al comienzo de la guerra civil tras el simulacro de un juicio por las milicias del Frente Popular.

${ }^{23}$ José Riva Aguero, Obras completas, Tomo II, p. 5.
} 
tina, insufló en la doctrina socialista un ánimo guerrero y místico ${ }^{24}$. Las nuevas generaciones de estudiantes hispano-americanos definían su oposición a los Estados Unidos y al imperialismo y concordaban en algunos aspectos sobre lo que opinaban los peruanos sobre su población. Así llegó José a coincidir con su ex compañero del Colegio de la Recoleta Francisco García Calderón cuando expresaba sobre la historia incaica lo siguiente:

La historia incaica -dice- tiene mucho de exótica y extraña para nosotros: No la sentimos con el afecto íntimo con que apreciamos la Colonia; para los descendientes de español carecen del atractivo de lo castizo, de lo que se refiere a la propia raza; y los descendientes de indios tampoco la aprecian mucho, porque han olvidado sus orígenes y en su conciencia étnica hubo con la conquista una verdadera y completa solución de continuidad ${ }^{25}$.

No hay que olvidar que en esos tiempos estos personajes pertenecientes a las clases altas de Lima y otras ciudades «hispanizadas» del Perú veían a indios, negros y mestizos como razas inferiores y referían la noción de raza circunscrita sólo al orden biológico y separada claramente de los conceptos de cultura, sociedad, pueblo, nación, lengua, etnia e incluso de población, cuya naturaleza y configuración no son de orden genético ni biológico ${ }^{26}$

Por su parte Riva Agüero en sus textos habla menos de la raza negra y, exceptuando unos pocos pasajes, tiende a ignorarla. Considera que no puede reconocérsele nada que se asemeje a un ideal literario u otras manifestaciones de cultura. Entre los caracteres fundamentales de dicha raza, que hace extensivo a los mulatos, menciona la petulancia y/o una indisciplinable turbulencia. En comparación con la raza india, la negra no tiene pasado ni origen y es presentada como la más primitiva de las razas que conforman el Perú, por su carencia de elementos de cultura. Ambos autores coincidían en que se necesitaba hacer un blanqueamiento de la población promoviendo el ingreso de inmigrantes españoles e italianos.

${ }^{24}$ José Carlos Mariategui, "1925. Dos concepciones de vida” publicado en el Mundial, Lima 9 de enero de 1925. Reproducido en José Carlos, Edición de Juan Marchena, Ediciones de Cultura Hispánica, Madrid 1988, p. 41 a 43. Manuel, González Prada, "El intelectual y el obrero" (1905) en Sobrevilla, op. cit., pp. 290-291.

${ }^{25}$ Tomado de Francisco Bobadilla Rodríguez. "José de la Riva Aguero y Osma o el intelectual antimoderno". Mercurio Peruano, N 520 UDEP, Piura, 2007, pp. 46-81.

${ }^{26}$ Véase «Francisco García Calderón: teoría de los dos Perúes», en Cultura Peruana (Lima), vol. XVI, n. ${ }^{\circ}$ 98, agosto de 1956, p. 66. 


\section{La conexión entre los reformistas de Córdoba de 1918 y los peruanos}

Desde muy temprano los estudiantes de la Universidad de Arequipa cuestionaban las deficiencias pedagógicas, económicas y administrativas de esa casa de altos estudios, por lo que decidieron declarar una huelga estudiantil. Posteriormente en los claustros de la Universidad de San Marcos se fundó el Centro de Estudiantes Universitarios, con dos representantes de cada una de las facultades. Esos hechos eran el preludio de las heroicas jornadas de la reforma universitaria de 1918-19 donde Juan Carlos Mariátegui tuvo un papel gravitante, al punto que los estudiantes solicitaron su nombramiento como catedrático, lo que obviamente no se concretó porque sus colegas no lo aceptaron. Y, por el contrario, en 1923 se produjo la expulsión de 26 estudiantes y la salida de Mariátegui.

Los estudiantes de vanguardia de la Universidad de San Marcos, leales a los principios de 1919 y 1923, sostuvieron en los años veinte temas similares a los de los jóvenes reformistas de Córdoba del '18: es decir salieron en defensa de la autonomía, innovación de métodos pedagógicos, instalación de universidades populares, etc. Y, manifestaban que los vicios existentes en las altas casas de estudios solo podían ser solucionados con la intervención de los alumnos en el gobierno de la universidad. Es decir, esto no era un fenómeno exclusivo y peculiar del Perú sino de varios países de América Latina. Ese movimiento reformista organizado potenció los lazos entre los estudiantes latinoamericanos y de estos con la clase trabajadora a través de variadas instancias: tales como las redes, las firmas de convenios o acuerdos bilaterales, los congresos de estudiantes y la correspondencia entre los líderes. Y las visitas de varios de estos al Perú en la década del veinte. El factor comunicacional cumplió una función relevante en el armado intelectual entre los estudiantes desde el mismo momento del inicio del movimiento reformista.

Riva Agüero y Osma, Víctor Andrés Belaunde y Víctor Raúl Haya de la Torre, fueron representantes de las nuevas ideologías de comienzos del siglo $\mathrm{XX}$, las cuales coincidían en sus posturas anticapitalistas y antiliberales. Ellos y otros fueron conscientes de su papel en el Perú y se autoproclamaban como una elite de poder con el fin de promover reformas, no solo educativas sino también sociales y políticas. A diferencia de González Prada que se contento con denunciar la situación, estos pasaron a la acción, no se conformaron con ser líderes espirituales, aun cuando vieron frustradas sus aspiraciones de hacerse con el poder ${ }^{27}$.

\footnotetext{
${ }^{27}$ Víctor Haya de la Torre, Por la emancipación de América Latina, M. Gleiser editor, Buenos Aires, 1927, p. 139
} 
Víctor Raúl Haya de la Torre, después de fundar la Federación de Estudiantes del Perú, fue arrestado y deportado; iniciando, en 1923, un viaje por América visitando Chile, Argentina y Uruguay. En Córdoba mantuvo relaciones con Deodoro Roca, líder de la reforma de 1918a quien visitó en el sótano de su casa, afirmando que era el argentino más brillante que había conocido y con Gabriel del Mazo en Buenos Aires, todos juntos bajo la misma bandera reformista. El destierro como el mismo afirmara era una forma de libertad, ya que en el Perú no existía ${ }^{28}$.

\section{La etapa del exilio europeo de Riva Agüero}

En 1918 de la Riva Agüero dictó una serie de lecciones sobre el Perú prehispánico en la Facultad de Letras de la Universidad de San Marcos; sin embargo, su etapa como catedrático sanmarquino fue muy corta.

Poco después de la instalación del régimen de Leguía y de manifestar su oposición al golpe de Estado de 1919 a través de la redacción de un manifiesto en defensa del orden constitucional Riva Agüero se exilió en Europa. Era el inicio de un periplo europeo que se extendería por España, Francia e Italia. Era la segunda vez que visitaba España, donde además de sus familiares que le permitieron relacionarse con parte de la nobleza, entabló amistades con escritores, historiadores y literatos. Tiempo más tarde mantuvo correspondencia con alguno de ellos durante la Guerra Civil. Por ejemplo, en junio de 1937, escribió al falangista Juan Manuel Fanjul una carta donde manifestaba su miedo por la campaña marxista y esperaba que sus paisanos reaccionaran contra esas propagandas forasteras y que los españoles, con su ejemplo, los liberaran de semejante amenaza. Estando en París en 1921 se enteró que era miembro de la Sociedad Menéndez y Pelayo.

Durante su estancia en Roma falleció su madre; más libre extendió su presencia en esa ciudad donde se relacionó con gente del gobierno y fue entonces cuando aparecieron sus arrebatos fascistas, tema por otra parte que sedujo a muchos otros peruanos de la época ${ }^{29}$.

\footnotetext{
${ }^{28}$ IDEM, Ibidem, p 34.

${ }^{29}$ Para ahondar en el tema ver Osmar Gonzáles Alvarado, "José de la Riva Agüero y Felipe Sassone: dos pensadores sociales y el fascismo en el Perú" Discursos Del Sur, N. o 6, julio/diciembre 2020, pp. 75-96. Jorge Wiesse Rebagliati, Los Viajes de Riva-Agüero, Lexis vol.43 no.1 Lima 2019.
} 
Imagen 1. Riva Agüero con el ministro de Italia en un acto público: Vittorio Bianchi.

Archivo Histórico Riva-Agüero. Instituto Riva-Agüero. Pontificia Universidad Católica del Perú.

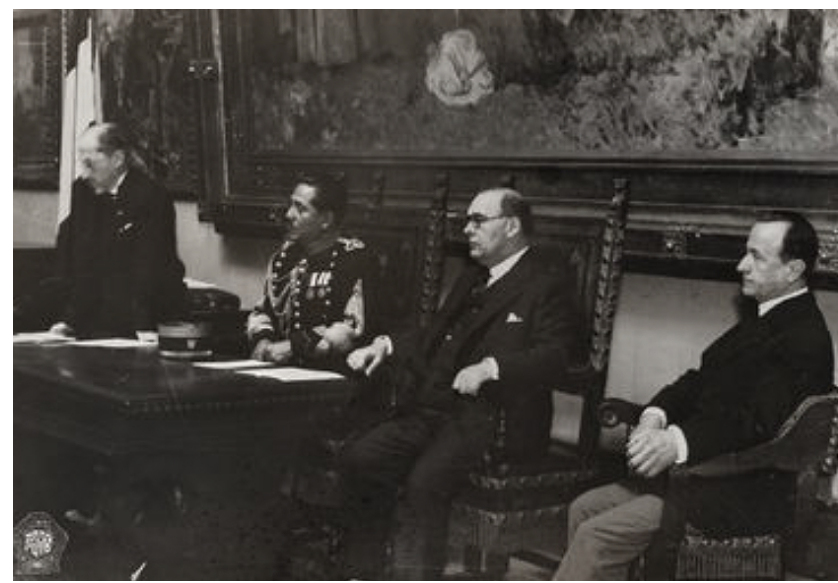

Su estadía en Europa se prolongaría hasta 1930, cuando retornó al Perú, luego del derrocamiento de Leguía a través de la rebelión militar encabezada por el comandante Luis M. Sánchez Cerro.

De su exilio en Europa conocemos lo que publicó en sus Obras Completas y algunos textos que se ocuparon del tema. De todos modos, lo interesante de destacar es que esa etapa marcó un viraje en sus ideas, dejando atrás el liberalismo racionalista en dirección hacia un integrismo católico. Recordemos que, en esos momentos había un rechazo al comunismo, lo que hizo que muchos otros peruanos lo acompañaran en su postura.

José y su vuelta al Perú

Riva Agüero vuelve al Perú justamente a la caída de Leguía en agosto de 1930, con escasos 45 años. Conjuntamente con él regresó, su ex compañero de estudios, Víctor Andrés Belaunde.

Riva Agüero traía la intención de participar en la vida pública del Perú, país que había cambiado notablemente de sus años mozos, en tanto no existía la sociedad como el recordaba, ahora había un movimiento obrero con fuerte tendencia socialista.

Estaba en pleno apogeo de su consagración intelectual, entonces pensó que gozaría de la aprobación de la sociedad limeña. Sin embargo, ocurrió todo lo contrario. Y ello se debía a que había muchos jóvenes que no lo conocían bien y otros que si sabían cuánto valía, pero, por animadversión de sus doctrinas, desataron contra él una campaña feroz acusándolo de retar- 
datario, de nostálgico del virreinato y de anti indigenista. Justamente a él que había demostrado su interés constante y afirmativo de lo indígena desde sus mismos años mozos, según lo hicimos notar. Si se analiza su obra literaria se comprobará que la mayor cantidad de páginas está dedicada a los periodos preincaico e incaico.

Cuando llegó era un erudito que propiciaba el trabajo y esfuerzo intenso, la investigación de primera mano, la faena intelectual sin vacilación y sin descanso, además de proclamar con ardor sus ideas, que sostenía a los cuatro vientos y enfrentaba a todos en cuanta ocasión se presentaba. Por todo eso tenía que chocar forzosamente con los débiles, los pusilánimes, con los acomodaticios, a los que él llamaría "menesterosos del idioma".

Ese año'30 escribió un artículo sobre La Universidad Católica y el Monopolio universitario donde atacó a la Universidad de San Marcos y el afán nivelador de los comunistas ${ }^{30}$ y criticó el monopolio universitario estatal porque le recordaba el afán nivelador de los bolcheviques ${ }^{31}$.

Dentro de su actividad política destacamos su condición de alcalde de Lima durante poco más de un año (1931-1932). En el '32, en un discurso en el almuerzo de los ex alumnos del Colegio Sagrados Corazones Recoleta, se manifestó contrario a los principios sostenidos en su juventud, abiertamente de derecha, haciendo un retorno a la religión católica. Entonces dijo:

En estos sugestivos claustros, testigos de mi niñez y adolescencia, viene mi madurez a renovar su consciente, razonada y pública adhesión a las tradicionales doctrinas que me educaron y que me son doblemente preciosas, por haberlas recuperado en larga y dura brega, tras de haberlas perdido. Beneficio inestimable, no concedido a todos ${ }^{32}$.

Luego ocupó el cargo de primer ministro y ministro de Justicia, Instrucción y Culto durante el gobierno del General Oscar R. Benavides, entre 1933 y 1934. Ejerciendo dicho puesto pronunció una alocución en ocasión de la clausura del año académico de la Universidad Católica en el '33, donde manifestó nuevamente su tinte anticomunista bien marcado. Sus cambios ideológicos, ahora con una destacada adhesión al catolicismo,conllevaron a su renuncia al no acordar con el gobierno la aceptación de la ley de divorcio

${ }^{30}$ J. Riva Agüero y Osma, Obras Completas, Tomo X, p.175 y 176.

${ }^{31}$ Aurelio Miro Quesada Sosa, "José de la Riva Agüero, un notable intelectual peruano", en El Comercio. 16 de noviembre de 1964. Fragmentos del mencionado texto en El Comercio, Nro. 51, Lima, 16 de marzo de 2014 suplemento dominical, p. D 4.

${ }^{32}$ J. Riva Agüero y Osma, Obras Completas, op, cit., 1932, p.371. 
por mutuo disenso. Para él la libertad de enseñanza era la libertad cristiana. Conforme iba pasando el tiempo las ideas de orden, autoridad, disciplina, jerarquía fueron ganando terreno ${ }^{33}$.

Posteriormente ocupó otros cargos: fue decano del Colegio de Abogados de Lima en 1936 y director de la Academia Peruana de la Lengua en 1933. También tuvo participación activa en las elecciones de 1936 (anuladas por el presidente Benavides) a través de la presidencia del movimiento Acción Patriótica que apoyó la candidatura de Manuel Vicente Villarán.

Su admiración del fascismo italiano de los años 30 no se convirtió en militancia fascista. Riva-Agüero privilegió el orden y la firmeza, pero no congenió con la revolución, ni con la asonada política. Para nuestro autor, el fascismo obedecía a una revolución moral. Él era más bien un hombre de derecha, nacionalista y corporativista. Así lo expresaba en un discurso en la agrupación electoral Acción Patriótica en 1936:

El camino hacia la organización corporativa, de que tantas veces os he hablado, supone una previa y ardua labor de reformas y reagrupaciones en lo constitucional, administrativo, gremial y económico ${ }^{34}$.

Entre sus actividades docentes dictó, en 1937 en la Universidad Católica, un curso de Historia de la civilización peruana prehispánica, destacándose entre sus discípulos más importantes los historiadores peruanos de larga trayectoria en el país como Don José Agustín de la Puente Candamo (Lima 19222020), Guillermo Lohmann Villena (1915-2005) y Pedro Benvenutto Murrieta (1913-1978).

Sus viajes por el Asia y Europa entre 1938 y 1940 le posibilitaron a Riva Agüero conocer de cerca el experimento dictatorial en Alemania, España e Italia. Convencido que esos regímenes eran un antídoto eficaz contra el comunismo, concitó su apoyo y admiración. Su postura anti-semita y sus alabanzas a Adolf Hitler y Mussolini hicieron que sus ideas autoritarias salieran a flote e incidieron para que los peruanos pronto lo olvidaran. Su admiración por el fascismo era evidente, al punto de escribir varios artículos en defensa de las potencias del Eje hasta su muerte.

José de la Riva Agüero falleció en Lima en 1944, dejando sus bienes como herencia a la Pontificia Universidad Católica del Perú. En 1962 dicha Universidad inició la publicación de sus Obras completas, con el "Carácter de

\footnotetext{
${ }^{33}$ Luis Gómez Acuna, op. cit. p. 104.

${ }^{34}$ Mecanografiado y manuscrito, cuadriplicado. Publicado en José RIVA AGÜERO, O.C., t. XI (ref. El Comercio, 23-3-1936, p. 5). AP.0027 s/f. s/l. Propaganda política.
} 
la literatura del Perú independiente", tesis con la que Riva-Agüero había optado el grado de bachiller en Letras en la Universidad Nacional Mayor de San Marcos, en el año 1905. Y, en el año 2007, esa institución editó su tomo 20 con un rico Epistolario que demuestra su conexión con importantes hombres del siglo como Marcelino Menéndez y Pelayo, a quien reconoce como su maestro principal y principal educador de su espíritu ${ }^{35}$, Miguel de Unamuno, José Enrique Rodo, y Luis E. Valcárcel, entre otros. Y entre sus coterráneos su correspondencia con Víctor Andrés Belaunde, Raymundo Morales de la Torre, Francisco y Ventura García Calderón, además de su propia familia. Además de las que mantuvo con sus colaboradores de sus dos proyectos políticos: el Partido Nacional Democrático (1915-1918) y Acción Patriótica (1936).

Estas epístolas han permitido que muchos escritores peruanos las estudiaran y se aproximaran a diversos momentos de la historia política, social, intelectual y de la vida cotidiana del Perú en la primera mitad del siglo XX. Don José cultivó a lo largo de su vida, y desde muy temprano, el arte de la correspondencia. Escritor asiduo, elegante y cuidadoso, guardó gran parte de las cartas y comunicaciones que le fueron remitidas, y tuvo la visión de conservar borradores ${ }^{36}$.

\section{A modo de conclusión}

Hemos analizado la vida del Dr. José de la Riva Agüero y Osma haciendo hincapié en su etapa de formación en Perú, y sus primeros pasos universitarios. En su etapa juvenil, observamos a un librepensador, que al igual que sus compañeros de estudios, tuvieron ideas progresistas para lo que era su país entonces.

Luego nos ocupamos de los años de su exilio en Europa y su posterior regreso a su país natal donde advertimos que las decepciones políticas, sociales e incluso personales influyeron en él. El Perú de los '30 era muy distinto al país que él dejó antes de partir. El gobierno de Leguía lo había trans-

${ }^{35}$ Víctor Samuel Rivera, "El marqués de Montealegre de Aulestia. Biografía española de un nacionalista peruano, en Escritos, vol. 17 Nro. 39 julio-diciembre de 2009.

${ }^{36}$ Las cartas pueden consultarse en el Archivo Histórico Riva-Agüero y suman más de 40.000 piezas documentales. Esta conducta era usual en los intelectuales de la época, pues sabemos que, por ejemplo, en el Perú hizo lo propio Ricardo Palma, Víctor Andrés Belaunde; Antonio Raimondi, publicados por el Fondo Editorial del Congreso de la República, entre otros. En Argentina, Cristina Vera está estudiando la correspondencia del líder de la reforma de 1918 Deodoro Roca y ha revisado la de German Arciniegas en Colombia, hombres contemporáneos a Riva Agüero. 
formado, los partidos políticos ahora estaban conformados por hombres de negocios, pragmáticos, lejos de aquellos donde él había participado con él consideraba hombres decentes, aristócratas e intelectuales.

Hacia el final de su vida su arrogancia, su postura anti-semita, sus alabanzas a Hitler y Mussolini hicieron que sus ideas autoritarias salieran a flote y le costaron que los peruanos lo olvidaran. Su admiración por el fascismo era evidente, al punto de escribir varios artículos en defensa de las potencias del Eje hasta su muerte. Sin embargo, al fallecer en 1944, no pudo presenciar el fin de la Segunda Guerra Mundial, ni rectificarse de sus posturas antidemocráticas.

$\mathrm{Su}$ trayectoria intelectual y su prolífica obra, nos hizo pensar que su figura merece revisarse, en tanto como miembro de la generación del 900 representa junto a otros el inicio del pensamiento socio político del Perúmoderno. A diferencia de Mariátegui y Haya de la Torre, de la Riva Agüero y Osma fue menos leído y profundizado y menos conocido en muchas partes de América, por lo que creemos que bien valían estas líneas.

\section{Bibliografia}

BELLINI GIUSEPPE (Universidad de Milán) "fortuna” literaria de Manuel González Prada en Thomas Ward / Richard CacchioneAmendola (EDITORES) Homenaje a Eugenio Chang Rodríguez, Universidad Ricardo Palma, Editorial de la Universidad, Lima, Perú 2017. pp.113.

Bustelo NATAlia, "Un fantasma que recorrió América Latina. A cien años de la reforma universitaria" en Revista Nueva Sociedad 275, mayo-junio de 2018.

CASTILla MARTin, "La generación arielista y la construcción del "otro" en el Perú del novecientos", en Revista: Los Trabajos y Los Días; año 3, no. 2, Facultad de Trabajo Social, La Plata, p. 141-149.

GonzÁlez MARCEla y [Comp.] Hacia los cien años de la Reforma Universitaria, Junta Provincial de Historia de Córdoba, Córdoba, 2018.

Gonzales Alvarado Osmar, "José de la Riva Agüero y Felipe Sassone: dos pensadores sociales y el fascismo en el Perú", en Discursos Del Sur, No 6, julio/diciembre 2020, pp. 75-96.

González Prada Manuel, Discurso del Politeama, 1888, p. 44. El discurso fue publicado primero en el periódico Sobrevilla y compilado después, en 1894, en el libro Pájinas[sic] Libres.Paris, Tipografía de Paul de Dupont, 1894 
González Prada Manuel, Páginas libres. Horas de lucha, Caracas, Biblioteca Ayacucho, 1985.

GonzÁlez Prada Manuel, «Propaganda i ataque», Amerika [En ligne], 17 | 2017, mis en ligne le 01 décembre 2017, consulté le 07 mars 2020. http:// journals.openedition.org/amerika/8236.

GómEZ AcuÑA, LuIs, Ideología y política en José de la Riva Agüero y Osma: los añosdejuventud. Tesis para optar al título de licenciado en Historia. Facultad de Letras, PUC, Lima 1997.

Gómez AcuÑa Luis "Ideología y política en José de la Riva Agüero y Osma: breves apuntes e hipótesis de estudio" en Histórica, 23(1), 1999, pp. 79-109. Recuperado a partir de http://revistas.pucp.edu.pe/index. php/historica/article/view/8700.

Haya De la ToRre Víctor, Por la emancipación de América Latina, Buenos Aires, M. Gleiser editor,1927.

MARIATEGUI JosÉ CARLOS, “1925. Dos concepciones de vida” publicado en el Mundial, Lima 9 de enero de 1925. Reproducido en José Carlos Mariategui, Edición de Juan Marchena, Ediciones de Cultura Hispánica, Madrid 1988, p. 41 a 43.

MARIATEGUI JosÉ CARLOS, Siete ensayos de interpretación de la realidad peruana [1928], Caracas, Biblioteca Ayacucho, 2007.

Miro Quesada Sosa Aurelio, "José de la Riva Agüero, un notable intelectual peruano", en El Comercio. 16 de noviembre de 1964. Fragmentos del mencionado texto en El Comercio, Nro. 51, Lima, 16 de marzo de 2014 suplemento dominical, p. D 4.

Riva AgüEro y Osmajosé, Obras Completas Editorial: Pontifica Universidad Católica del Perú, Lima, Perú, 1965.

Riva AgüEro y Osmajosé, Obras Completas. Tomo 20. Epistolario: NachbibOyague y Joyero. Lima: Fondo Editorial de la Pontificia Universidad Católica del Perú, Instituto Riva-Agüero, 2007.

RiVERA Víctor SAMUEL, "El marqués de montealegre de aulestia. Biografía española de un nacionalista peruano", en Escritos, vol. 17 Nro. 39 juliodiciembre de 2009.

Sánchez Luis Alberto, Mito y realidad de González Prada Lima: P.L. Villanueva Editor, 1976.

Segundo Coloquio Internacional dedicado a González Prada, "Manuel González Prada y el liberalismo" en la ciudad de Baltimore, Maryland, Estados Unidos. 2008, consultado en línea.

Vera de Flachs María Cristina, Un precedente de la reforma del '18: el I Congreso internacional de estudiantes americanos. Montevideo 1908" 
en Junta Provincial de Historia de Córdoba, Movimientos Estudiantiles en América y Europa, Tomo I, capítulo I, 2006, pp. 73 - 114.

VERA DE FlaChS MARÍA C., La reforma universitaria de córdoba de 1918. Desde el espíritu de círculo a su impacto en América Latina en la década del veinte, Perú 2021, en imprenta en la Universidad de Piura.

VERA DE FlaChs MARía C., La Ciencia Joven. Prosopografia y producción científica de los academicos alemanes de la Universidad de Cordoba. 18701900, Cordoba, Junta Provincial de Historia de Cordoba, 2002.

VERA DE FlaChS MARÍA C., "Un español republicano en Argentina: Juan BialetMassé. Sus textos de anatomía y manual de Medicina Legal” en Manuales y Textos de enseñanza en la universidad liberal. Universidad Carlos III, Madrid, 2004.

Ward Thomas / CACChioneAmendola Richard (EDITORES) Homenaje a Eugenio Chang Rodríguez, Universidad Ricardo Palma, Editorial de la Universidad, Lima, Perú 2017.

Wiesse Rebagliati Jorge, "Los Viajes de Riva-Agüero", Lexis, vol.43 No.1, Lima 2019. 